\title{
Influence of Technological Parameters on the Dimension of GEAR Parts Generated with PLA Matherial by FDM 3D Printing
}

\author{
MIRCEA DORIN VASILESCU*, TRAIAN FLESER \\ Politehnica University Timisoara, 2 Victoriei Sq., 300006, Timisoara, Romania
}

\begin{abstract}
The purpose of this research is to establish the technology of 3D printable production on the principle ofFDM of gears made of PLA, ABS and PETG mainly. In the paper we present first the dimensional generation and specific aspects that need to be considered to produce gears with internal or external teeth of the cylindrical type with vertical or inclined teeth. Generating the gears appeared as a necessity for the reconditioning of the components of the processing machines and of the electric machines made both in the process of elaboration of the bachelor's and the laboratory works, with reduced energy resource consumption and low pollution as low as possible. After the construction, we past to identify the dimension that have implications for both mechanical and kinematic resistance to achieve a product with good cinematic and functional characteristics. After that are made an analysis of the layers generated, both from the computer simulation and from the point of view of the analysis of layers physically generated on a gear tooth with external teeth.
\end{abstract}

Keywords: 3D printing; fabrication parts; dimension gear, PLA material, FDM printing

Obtaining parts that have a structure composed of type gears is a complex and relatively difficult process of processing especially when the difference in diameters is large or very large (fig. 1.). From the areas in which such components with maximum economic efficiency can be used, we list those of repairing components made of metallic or non-metallic materials, in which the mechanical stresses are reduced or have average values [1-4]. From both the experimental and the specialized literature, we can conclude that there are a few materials that can be used successfully to achieve these goals.

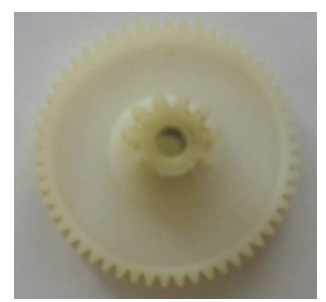

Fig. 1.Geometry gear 3d printed

The study is geared both to determine the technological efficiency for the implementation of PLA, ABS and PETG materials for the making of 3D toothed parts by FDD (Fused Deposition Modelling) $[5,6]$ technology, as well as the realization of components under the new imposed conditions using materials and recyclable technologies that pollute less the workspace. The polluting factor must be seen both from the point of view of the energy resources used to obtain the raw material and from the point of view of the reintroduction into the industrial circuit of the material that was used in the toothed wheel components by recycling the damaged wheel material method, (Life Care Assessment) [7, 8].

From the point of view of these three materials, as can be seen from (table 1), the materials considered have similar resistance characteristics. It can be seen from the analysis that the best compressive strength is PLA and approximately the smallest elongation at break, respectively the highest modulus of elasticity betw een the three materials. This conclusion leads us to assert that the first recommended material would be PLA [9-12] for toothed wheels, followed by PETG and finally due to the large range of different $A B S$ values.

If we compare the values of compressive strength from (table 1) with those of aluminium or castiron, we find that they are comparable (table 2 ).

Table 1

MATERIAL PROPRIETIES FOR 3D PRINTING

\begin{tabular}{|l|l|l|l|l|l|l|}
\hline Material & $\begin{array}{l}\text { Dens. } \\
\text { in } \\
\text { gr/cm }\end{array}$ & $\begin{array}{l}\text { UTS in } \\
\mathbf{M P a}\end{array}$ & $\begin{array}{l}\mathbf{C S} \text { in } \\
\mathbf{M P a}\end{array}$ & $\begin{array}{l}\mathbf{E} \text { in } \\
\mathbf{G P a}\end{array}$ & $\begin{array}{l}\text { IS in } \\
\mathbf{J} / \mathbf{m}\end{array}$ & $\begin{array}{l}\mathrm{EB} \text { in } \\
\%\end{array}$ \\
\hline $\begin{array}{l}\text { PLA } \\
{[13,14]}\end{array}$ & 1.24 & 50 & 153 & 3.5 & $15-45$ & 6 \\
\hline $\begin{array}{l}\text { PETG } \\
{[15,16]}\end{array}$ & 1.29 & 53 & 55 & 2.1 & 77 & 18 \\
\hline $\begin{array}{l}\text { ABS } \\
{[17,18]}\end{array}$ & $1.0-1.4$ & $37-110$ & 65 & $2.0-2.6$ & $70-370$ & $3.5-50$ \\
\hline
\end{tabular}

UTS is Tensile Strength: Ultimate, CS is Compressive (Crushing) Strength, E is Elastic (Young's, Tensile) Modulus, IS Impact Strength: Notched Izod, Dens. is Density, EB is Elongation at Break

It can be concluded from this analysis that, from the point of view of the compression resistance, the two types of printed and non-metallic or metallic materials, are with compression resistance in the domain of relatively same values, while from the point of view of the breaking requests, the differences are relatively large three to four times smaller.

Table 2

NON METALIC AND METALIC MATERIAL PROPRIETIES

\begin{tabular}{|l|ll|l|l|l|l|}
\hline Material & $\begin{array}{l}\text { KR. in } \\
\mathbf{M P a}\end{array}$ & $\begin{array}{l}\text { UTS in } \\
\mathbf{M P a}\end{array}$ & $\mathbf{C S}$ in MPa & $\begin{array}{l}\text { RI in } \\
\mathbf{G P a}\end{array}$ & $\begin{array}{l}\mathrm{EB} \\
\text { in } \\
\%\end{array}$ \\
\hline $\begin{array}{l}\text { Aluminium } \\
6082[19]\end{array}$ & $\begin{array}{l}140 \\
330\end{array}$ & -290 & $28-66$ & $31-72$ & 10 \\
\hline $\begin{array}{l}\text { Aluminium } \\
6063[20]\end{array}$ & $\begin{array}{l}145 \\
186\end{array}$ & -241 & $29-37$ & $31-41$ & 12 \\
\hline $\begin{array}{l}\text { Aluminium } \\
\text { A380 [21] }\end{array}$ & $\begin{array}{l}160 \\
325\end{array}-$ & 290 & $32-65$ & $35-72$ & 35 \\
\hline $\begin{array}{l}\text { Greycast } \\
\text { iron [22] }\end{array}$ & $\begin{array}{l}150 \\
400\end{array}$ & $-160-450$ & $570-1290$ & $49-125$ & 0.5 \\
\hline
\end{tabular}

KK IS breakıng KesIstance, $K I$ IS benaing kesIstance 
This causes 3D printed materials to be used primarily in areas where the requests are small or medium, and if used for larger value of resistance, requests the size of the material should be increased or ensured the hardening of the structure with elements of metal or non-metallic carbon fibre support

\section{Considerations on the generation of Gears for 3D printing}

For the performance of gears wheels through 3D printing, it should be considered that it is recommended in terms of tooth geometry a tooth with a pressure angle of 25 to 35 versus 15 degrees as it is for the gears wheels generated by injection or 20 degrees for the ones generated on the dental machines. The advantage of such grease is determined by the fact that the base of the tooth is much underline. In (fig. 1.) a gear wheel which is the subject of this work carried out in Inventor 2017 [22] may be observed.

To be able to achieve effective geometry corrections, from the point of view of contractions or expansions, but also for geometrical considerations, it is recommended that the determination of dimensional quota values, be achieved using the generation module parameterized name function module (fig. 2.) of each of the gear covered by the generation of the wheel assembly after which the gears assembly will be generated (fig. 3.).

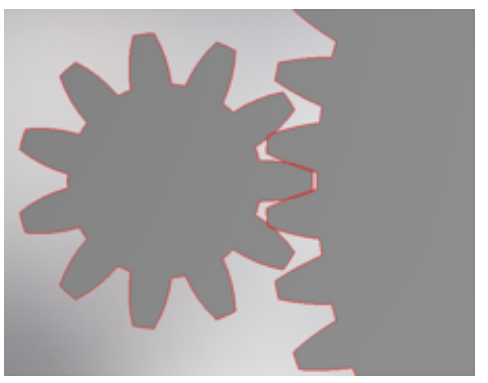

Fig. 2. Geometry gear 3D printed

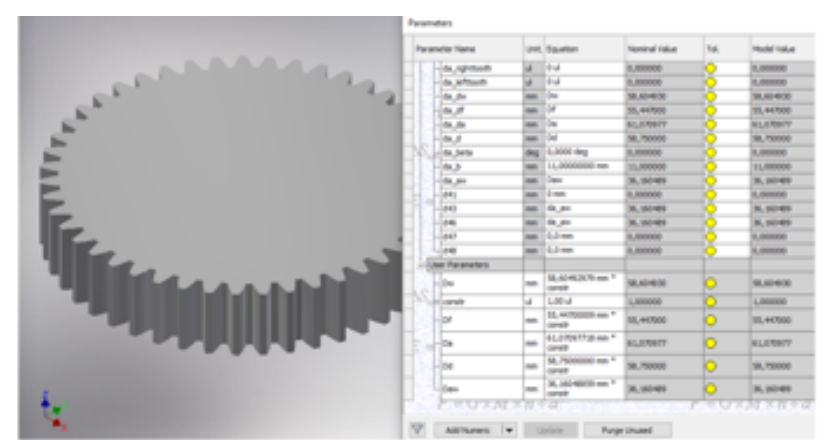

Fig. 3. Gear wheel parameterized generation

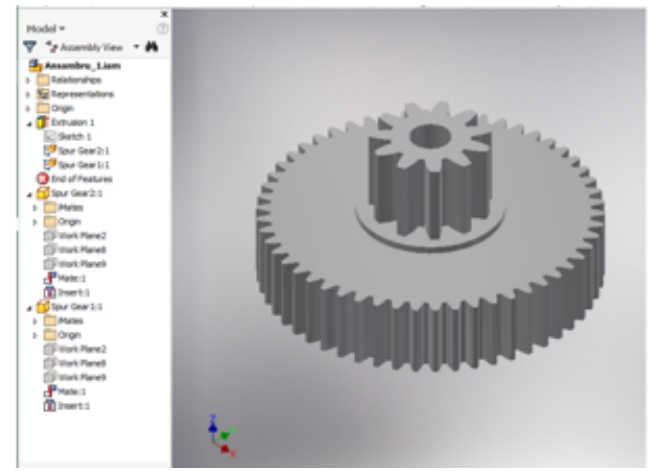

Fig. 4.Gears Wheels Assembly

A second very important element in the sizing part of the gears wheel is that of corrections due both to the dilates occurring because of the deposition of peripheral layers to the outside that will produce changes in the size of the wheel teeth Gears, but also changes in the distance between the wheels. It can also be seen that in the vertical direction the phenomenon of contraction is much less important than the one on the other two directions.

It can be seen in (fig. 4) that the generation is achieved by positioning the coaxial and surface contact constraints and at the same time by positioning a ring intermediary element to achieve a hardening element of small wheel teeth relative to those of the big wheel.

\section{Considerations on the implementation of the 3Dprinting machine control program}

To be able to achieve the $3 \mathrm{~d}$ printer's kind of command program it is primarily necessary to have a file generated by type STL (abbreviation of the name Stereolithography) [23].

The way of the generation of this file is accomplished to be very important. Generally, if the settings for generating the file are not correctly chosen, errors may occur when $3 \mathrm{~d}$ printing of the missing type of material, ranges, and part defects. Also, before the printing CAM program is made, the STL file is required to be verified from the point of view of generating the triangular structure, with one of the known verification programs. In our case to be joined, we will use one of the programs made available by AUTODESK company, namely Netfabb [24], which ensures that the STL file is loaded, if the automatic correction of the file geometry (fig. 5.) is set as the default. However, there is also the option to make verification after the load of the file and then to verify the integrity of the structure.

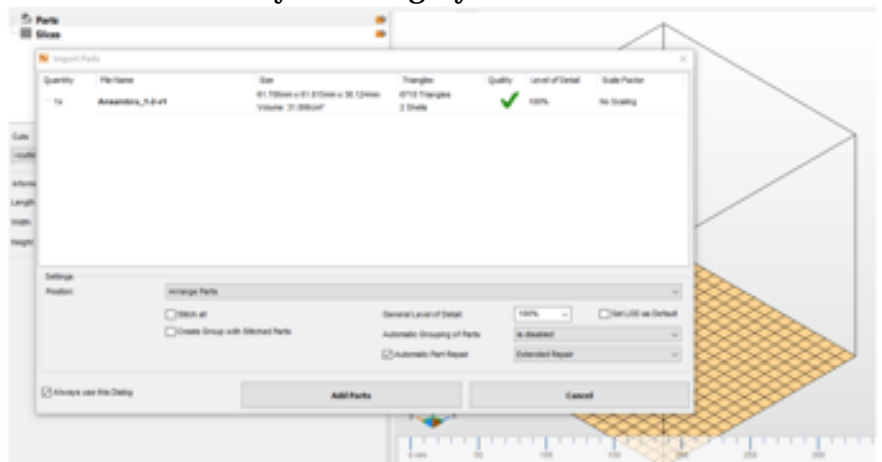

Fig. 5.Netfabb gear STL correction for 3D printed part In figure 6 is save the repaired file in STL form.

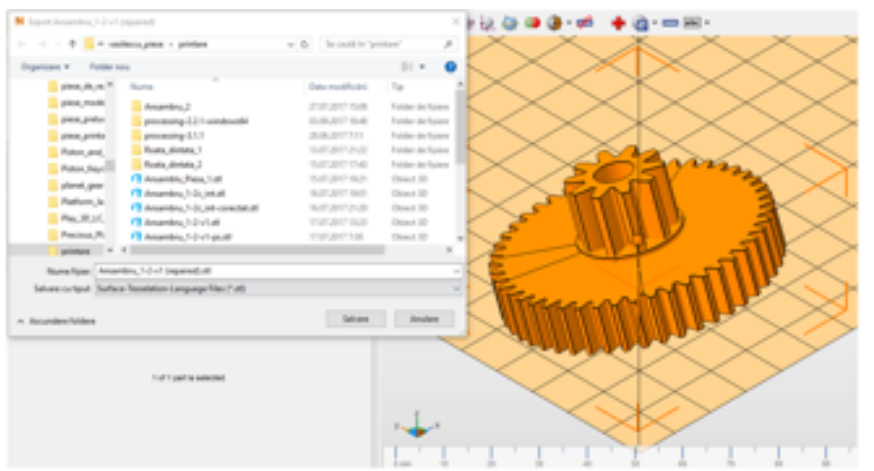

Fig. 6.Netfabb Save corrected file

The latter is one of the important operations without which it cannot be guaranteed to obtain a gear with appropriate features when printing $3 \mathrm{~d}$. The STL file thus realized will need to be loaded into the layer generation program. One of these programs is the Cura from Ultimaker [25], which still ensures the operation of layer generation. In (fig. 7.) It is possible to see the geometrically laden element and positioned to perform the processing code generation operation. 


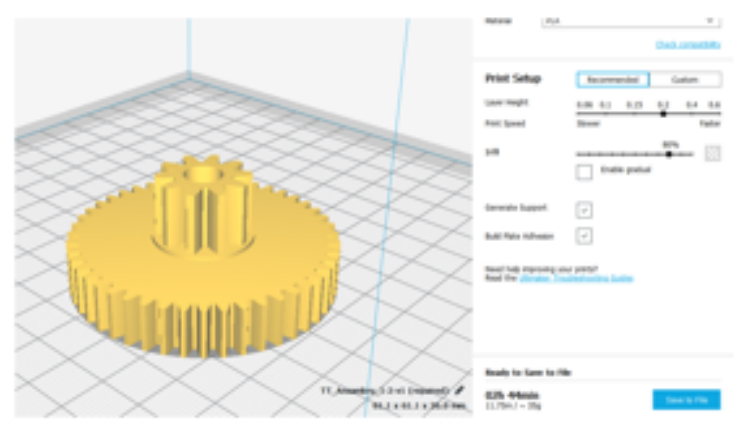

Fig. 7.Gear positioned for 3D printing

It is possible to see that for default standard states the print duration is $2 \mathrm{~h}$ and $44 \mathrm{~min}$. If it is visualizing the generation screens, the first layer (fig. 8) and an intermediate layer of 27 layer ( fig. 9) can be seen that the program recommends for better realization of the wheel geometry in the first layer to activate the generation of a support area of Blue colour that ensures good adhesion of the wheel edges without any distorted areas of the type (fig. 8). The solution is more than necessary for ABS material, but it is also recommended for other materials.

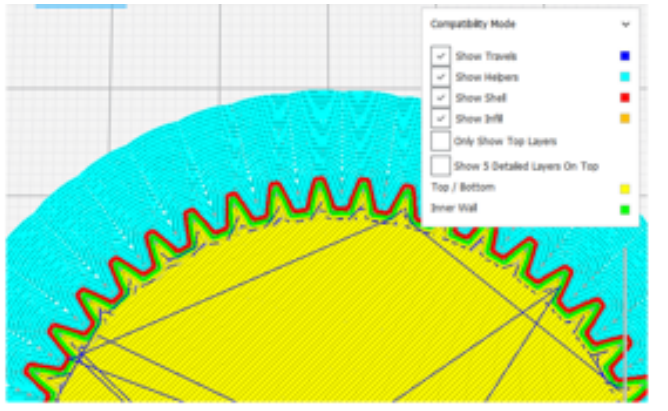

Fig. 8.First layer generated for 3D printed gear

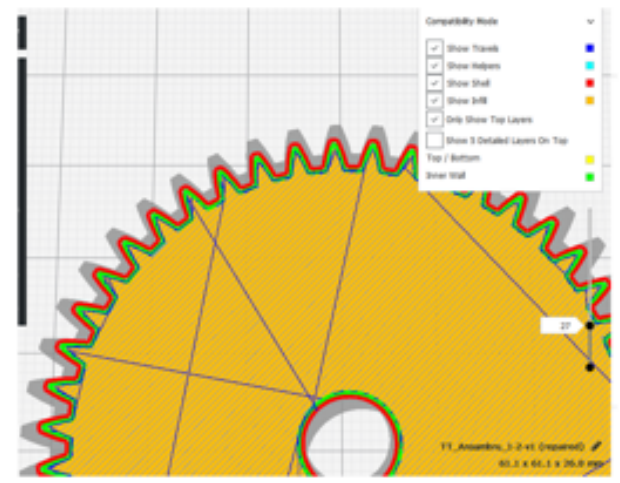

Fig.9.Gears generation layer 27

It is possible to see that a few problems that occur in the generation. The first is determined by the area between the continuous layers arranged on the exterior of the red gears wheel and the one parallel to it on the inner side of the green colour and the base structure part. This will cause the tooth not to have a homogeneous structure in the resistance side of the tooth with negative effects on its resistance. If we analyse and the tooth generated in the 74 layer, this can be seen even more prominently (fig. 10.).

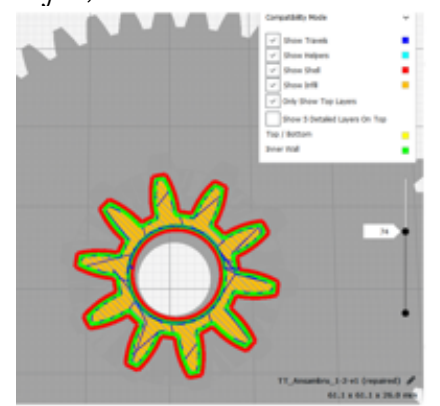

Fig. 10.74 layers generated for making a gear
The analysis of the two types of gears shows that the number of perimeter contours depends on the module of the gears, in smaller way fewer teeth, and in the larger way more contours perimeter. For the analysed case we have two wheels with different mode. The small has a module of 1.25 while the big has a module 0.8 .

The Cura 3.3.1. program can set different parameters for various range of parts generated. It should be considered that we have two distinct areas and strategies can be targeted or on generating two overlapping parts that will have different generation settings, or on separating a whole unit into two cylindrical areas with different settings.

In practice it can be use several variants of generation in the Cura 3.3.1. of two separate parts. A geometric cylindrical element that will be introduced for the delimitation of the two elements subject to the $3 d$ generation can be generated, or the two geometric elements that are overlapping and which will subsequently be set for printing with different parameters.

Both variants produce rigid separation plans between them of the top plan and bottom plane type that may in certain situations produce unwanted effects. It is proposing to analyse these variants in a work in which to analyse and the testing that can be taken by the two variants compared to the standard variant with several perimeter lines that we will further detail.

For our case we will choose the variant with 4 perimeter lines and present for the same layers and processing parameters the appearance of the periphery of the teeth.

In (fig. 11) are presented the selected generation parameters for layers in the original variant Line width 0.4 , and in (fig. 12) those who are selected for Line width 0,5 variant. The first conclusion is to reduce the print time at 2 $\mathrm{h}$ and $11 \mathrm{~min}$ from $2 \mathrm{~h}$ and $41 \mathrm{~min}$.

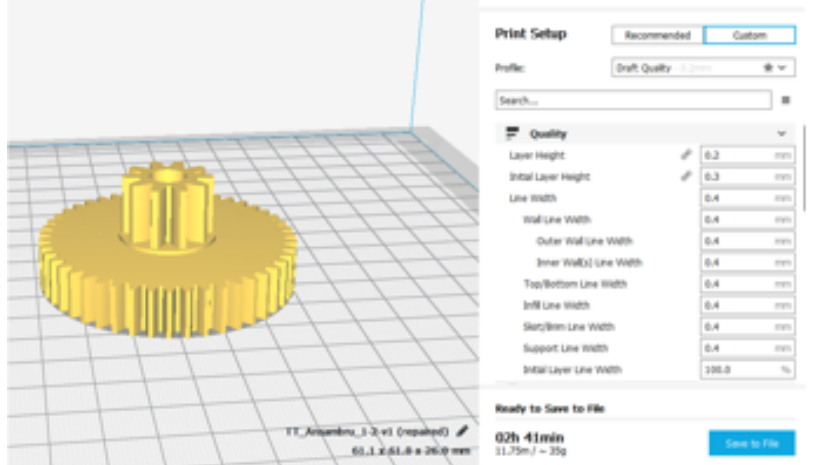

Fig. 11.Initial solution for Line width $0.4 \mathrm{~mm}$

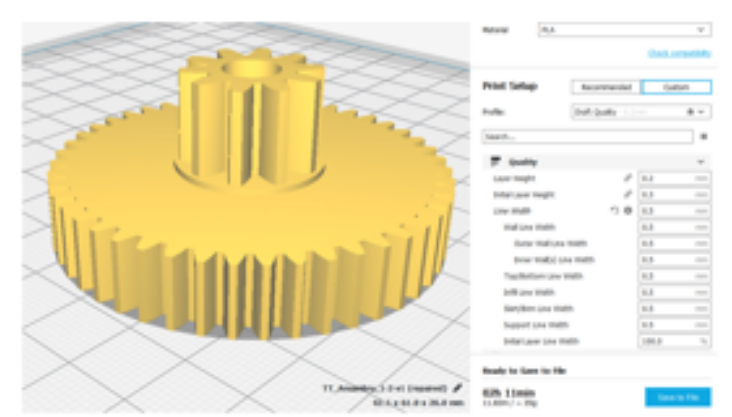

Fig. 12.Solution for Line width $0.5 \mathrm{~mm}$

If it is visualizing the generation screens, the first layer (fig. 13) and an intermediate layer of 27 layer (fig. 14) can be seen that the program recommends for better realization of the wheel geometry in the first layer to activate the generation of a support area of Blue colour that ensures good adhesion of the wheel.

If we analyse and the tooth generated in the 74 layer, this can be seen even more prominently (fig. 15.). 


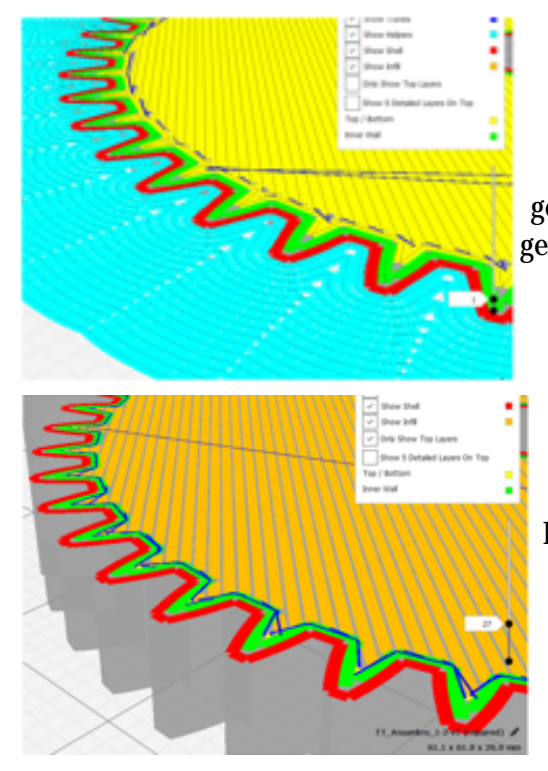

Fig. 13.First layer generated for 3D printed gear for Line width $0.5 \mathrm{~mm}$

Fig. 14. Gears generation layer 27 for Line width $0.5 \mathrm{~mm}$

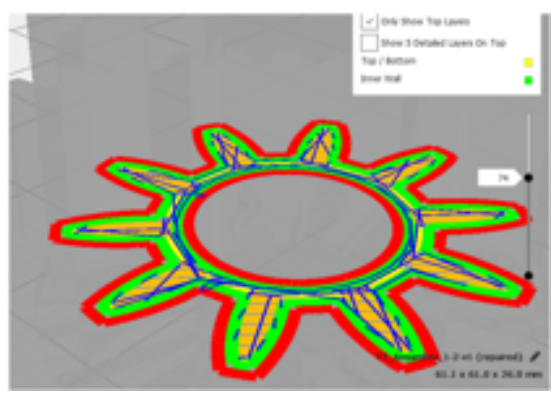

Fig.15. 74 layers generated for making a gear for Line width $0.5 \mathrm{~mm}$

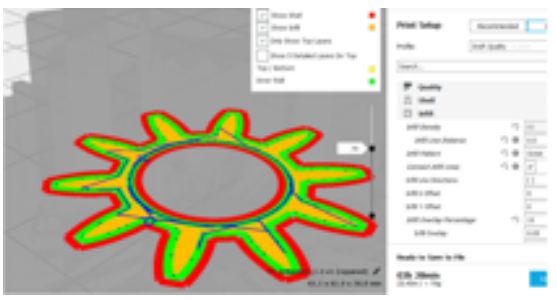

Fig. 16 . 74 layers generated for making a gear for Line width $0.5 \mathrm{~mm}$ Infill Octet

The proposed change shows an increase in the thickness of the peripheral lines with beneficial effects on the mechanical strength of the teeth. Another solution is that of changing the geometric shape of the internal lines in the byte with a distance between lines of $0.5 \mathrm{~mm}$. An increase in the duration of printing to $3 \mathrm{~h}$ and $28 \mathrm{~min}$, but also the amount of wire from $35 \mathrm{~g}$ to $70 \mathrm{~g}$, so a better filling of the wheel teeth at both the upper (fig. 16) and the lower part (fig. 17).

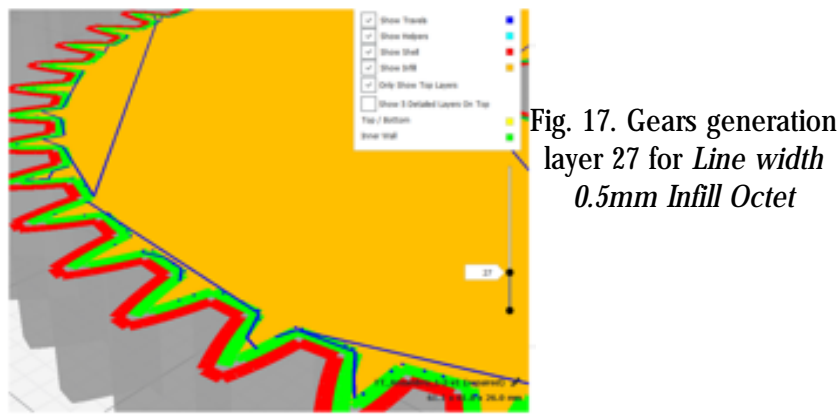

\section{Gear generated with 3D printing}

A Fabrikator Mini [2] printer was used for printing. In (fig. 18) one of the variants of the generated gear that has been proven during the tests carried out on the machine that has undergone the resistant repair process can be observed. It should be noted that it is recommended that both the storage phase of it and the conditions under which it is used should not be with high humidity for the wheels of the PLA. 
9.VASILESCU, M. D., GROZA, I.V., Influence of technological parameters on the roughness and dimension of flat parts generated by FDM 3D printing, Nonconvenional Technologies Review, 2359-8646, vol.3, pp.18-23, 2017

10.VASILESCU, M.D., Theoretical consideration on the abrasive watermixing chamber made by the PLA material with $3 \mathrm{D}$ printing process by FDM type, Nonconvenional Technologies Review, 2359-8646, vol.1, pp.36-41, 2018

11.RAPA, M., DARIE NITA, R.N., VASILE, C., Influence of plasticizers over some physico-chemical properties of PLA, Mat. Plast, 54, no.1, 2017, p.73

12.POPESCU, A., ENCIU, G., DOBRESCU, T., PASCU, N. E., Experimental research using the $3 D$ printing technology with plastic materials for prehension systems JAWS, Mat. Palst., 55, no.1, 2018, p. 20

13.*** - https://www.makeitfrom.com/material-properties/PolylacticAcid-PLA-Polylactide, access 2018.

14.*** - https://plastics.ulprospector.com/generics/34/c/t/polylacticacid-pla-properties-processing, access 2018

15.*** - https://www.sd3d.com/wp-content/uploads/2017/06/ MaterialTDS-PETG_01.pdf, access 2018
16.*** - https://www.makeitfrom.com/material-properties/GlycolModified-Polyethylene-Terephthalate-PETG-PET-G, access (2018).

17.*** - https://www.makeitfrom.com/material-properties/ Acrylonitrile-Butadiene-Styrene-ABS, access 2018

18.*** http://www.teststandard.com/data_sheets/ABS_Data_sheet.pdf, access 2018

19.***http://www.matweb.com/search/datasheet_print.aspx?matguid= fad29be6e64d4e95a241690f1f6eleb7, access $201 \overline{8}$

20.*** - https://www.makeitfrom.com/compare/6061-AlMg1SiCu-3.3214H20-A96061-Aluminum/A380.0-A380.0-F-SC84C-A13800-Cast-Aluminum, access 2018

21.*** - https://www.makeitfrom.com/material-properties/Grey-CastIron, access 2018

22.*** - INVENTOR 2017, access (2017).

23.*** - https://all3dp.com/what-is-st-file-format-extension-3d-printing/ , access 2018

24.*** - https://www.autodesk.eu/products/netfabb/overview, access 2018

$25 . * * *$ - https://ultimaker.com/en/products/ultimaker-cura-software, access (2017)

$\overline{\text { Manuscript received: } 12.03 .2018}$ 